\title{
CONTRIBUIÇÕES DE ANGEL PINO PARA PENSAR O HOMEM NOVO EM VIGOTSKI
}

\author{
Anna Maria Lunardi Padilha*
}

\begin{abstract}
RESUMO: Este texto tem por objetivo apontar algumas contribuiçóes de Angel Pino para a compreensão do conceito de homem novo proposto por Lev Vigotski. Esse conceito está estreitamente vinculado ao pensamento de K. Marx e F. Engels e dele deriva. Vigotski propóe que a cultura é produção humana, de modo que o homem produz a própria vida e a modifica conforme as suas necessidades e as condiçóes históricas. Em várias obras, Angel Pino retoma e explicita, com rigor teórico e aprofundamento em vários campos do conhecimento, que as condiçóes de existência, de onde origina a consciência dos homens, são transformadas pelo homem e, para isso, ele inventa e utiliza instrumentos e signos. O esforço de Angel Pino em direção à compreensão da teoria de Vigotski sobre a passagem da ordem do desenvolvimento natural para o cultural é inspiração para pensar a passagem de uma sociedade que explora e priva seus membros dos bens materiais e culturais para uma nova sociedade constitutiva de um novo homem.
\end{abstract}

Palavras-chave: Lev Vigotski. Angel Pino. Homem novo. Transformação socialista. Psicologia histórico-cultural.

* Universidade Metodista de Piracicaba (Unimep), Programa de Pós-graduação em Educação. Piracicaba, S.P., Brasil. E-mail de contato: ampadilh@unimep.br 


\title{
Angel Pino's contributions to reflect on the new man in Vigotski
}

\begin{abstract}
This text aims to point out some of Angel Pino's contributions to the understanding of the concept of new man proposed by Lev Vigotski. This concept is closely linked to K. Marx's and F. Engels's thinking and derives from it. Vigotski proposes that culture is a human production and that the man produces his own life and modifies it according to his needs and historical conditions. In several works, with theoretical strictness and depth in various fields of knowledge, Angel Pino retakes and makes it explicit that the conditions of existence, from which the man's consciousness originates, are transformed by him and for that he invents and uses tools and signs. Angel Pino's effort towards the understanding of Vigotski's theory on the passage from the order of the natural development to the cultural one is inspirational to reflect upon the passage of a society which exploits and deprives its members from the material and cultural goods to a new society, constitutive of a new man.
\end{abstract}

Keywords: Lev Vigotski. Angel Pino. New man. Socialist transformation. Cultural-historical psychology.

\section{INTRODUÇÃO}

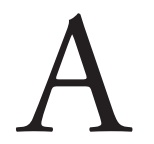

sociedade está privando pessoas. Desse ponto de vista, pode-se discutir privação. Num determinado contexto cultural, existe uma limitação de possibilidades. Só que essa limitação contextual não quer dizer que a pessoa esteja enjaulada no contexto. Ela vai além, mas precisa de condiçóes ${ }^{1}$. Em uma das aulas do professor Pino, no programa de Pós-graduação em Educação, na Unicamp, perguntávamos sobre a privação de bens materiais e simbólicos a que muitas pessoas estáo submetidas em uma sociedade capitalista como a nossa, e suas consequências para o desenvolvimento cultural - tema central da aula. Não se tratava de privação no sentido de valorização de uma cultura em detrimento de outra, ou de falta de cultura de quem nasceu nessa ou naquela região do mundo. Nem de carências de ordem física ou mental 
das camadas empobrecidas da população, pois, nesse caso - explicou o professor - estaríamos longe do conceito de cultura de Vigotski ${ }^{2}$ - autor que Pino estudou com rigor e paciência.

Tenho me colocado, ao lado de muitos estudiosos, o problema da degradação do homem pela/na sociedade capitalista, que não é senão produtora de mercadoria e que faz das relaçóes humanas relaçóes entre coisas. Marx, Engels e Vigotski são autores de especial importância para as reflexôes sobre a constituição cultural e histórica da consciência. De tal modo que, pensar, por meio de seus ensinamentos, em uma sociedade livre da expropriação, em outros termos, livre da privaçáo dos bens materiais e simbólicos conquistados pela humanidade, impele-nos a lutar pela superação dessa realidade. Angel Pino sempre se preocupou com as condiçóes de exploração do homem pelo homem e objetivava teorizar sobre as possibilidades de tais superaçóes, indo além das aparências dos fatos, fiel ao materialismo histórico-dialético. Afirmou que temos enormes desafios diante da realidade social e educacional que só poderão ser enfrentados quando se resolver a contradição estrutural que afirma e nega, ao mesmo tempo, os direitos das pessoas. Daí ser preciso repensar "[...] a relação escola-trabalho de maneira a superar a dualidade saber/ fazer e a instrumentalização da escola em função dos interesses do capital [...]”. (PINO, 1992, p. 23) [grifo do autor]

Vigotski, coerente com a matriz do materialismo histórico-dialético, concebia cultura como o conjunto das obras humanas, cuja significação constitui o que é específico de tais obras. Em As Marcas do Humano, escrito alguns anos após a aula à qual me referi, Pino esclarece:

[...] ora, na medida em que a cultura é o conjunto das obras humanas e o específico dessas obras é a sua significação; o desenvolvimento cultural da criança é o processo pelo qual ela deverá apropriar-se, pouco a pouco, nos limites de suas possibilidades reais, das significaçóes atribuídas pelos homens às coisas. Mas 0 desenvolvimento cultural estará comprometido se ela não tiver também acesso aos bens materiais produzidos pelos homens e que são portadores dessas significaçôes. (PINO, 2005, p. 152) [grifo meu] 
É coerente irmos a Marx e Engels (1996, p. 37) a fim de explicitarmos a matriz de sua afirmação. "O ser dos homens é o seu processo de vida real [...]”. E ainda: “[...] os homens, ao desenvolverem sua produção material e seu intercâmbio material, transformam também, com esta, sua realidade, seu pensar e os produtos de seu pensar. Não é a consciência que determina a vida, mas a vida que determina a consciência”.

Lembrando que, para Vigotski, "Cultura é o produto, ao mesmo tempo, da vida social e da atividade social do homem [...]", Pino (2005, p. 89) explica que "Nesse enunciado tão simples, Vigotski está afirmando duas coisas: 1) que a cultura é uma 'produção humana' e que 2) essa produção tem duas fontes simultâneas: a 'vida social' e a 'atividade social do homem"'. O homem que produz cultura produz a própria vida e a modifica conforme suas necessidades e possibilidades. As condiçóes de existência, de onde origina sua consciência, são transformadas pelo homem que, para isso, inventa e utiliza instrumentos e signos - objetivaçóes de seu trabalho.

A intenção de refletirmos - mesmo diante das limitaçóes advindas da necessidade de um recorte - acerca do sentido de transformação que propôs Vigotski quando escreveu A Transformação Socialista do Homem, em 1930, tem inspiração nas aulas, na convivência acadêmica e afetiva e, claro, na obra do pensador, professor e pesquisador Angel Pino.

\section{O CAMINHO DA REFLEXÃO}

No tempo das aulas com o professor Pino, o aprendizado do olhar e da escuta. Na vida acadêmica, o aprendizado do movimento incessante em direção ao conhecimento e, como Pino alertava, caminhando "em busca de explicaçóes ainda distantes". Não temendo ir fundo nas questôes que abordava, ele nos trouxe conhecimentos de vários campos de estudo, na tentativa de fazer articulaçóes complexas entre teorias. Estudou Filosofia, Antropologia, Sociologia, Psicologia, Educação, Semiótica e nos apresentou muitas vezes estudos sobre a história do conhecimento com autores de diferentes épocas e posições epistemológicas. 
Esse destemor indica, pelo menos, três esferas do trabalho intelectual de Angel Pino: o profundo conhecimento dos clássicos a quem recorria; o esforço de fidelidade à matriz marxista da perspectiva histórico-cultural e o rigor metodológico em sua exposição. Afirmou que, para estudar a obra de Vigotski, é necessário ir além do mundo sensível, contradizendo, corajosamente, um dos ensinamentos pós-modernos que insistem em (re)configurar a fenomenologia. Referia-se com clareza aos princípios marxianos nos estudos de Vigotski.

Como sua obra está viva, encontro, na memória da voz e nos ensinamentos pela escrita, motivação para escrever alguns apontamentos a partir do que identifico como esforço de fidelidade à matriz marxista da perspectiva histórico-cultural. Ele diz: "[...] lembro ao leitor que a tese de Vigotski que orienta minhas reflexóes situa-se no contexto do materialismo histórico e dialético, na linha de Marx e Engels, como ele [Vigotski] mesmo afirma em vários de seus trabalhos [...]". (PINO, 2005, p. 16) Coerente e sempre em busca de explicaçóes, Pino marca posição, novamente, quando escreve, a propósito do bicentenário do nascimento de Darwin, que é preciso ir além:

[...] dos atuais limites da biogenética e da neurologia, da paleontologia e da etnologia, da antropologia e da psicologia e de outras ciências, para pensar o homem como um ser completo, haveríamos de caminhar pela via do materialismo histórico e dialético de Marx e Engels, traduzido na nova visão do ser humano presente nos trabalhos de Vigotski (1997) e Vigotski e Luria (1992), entre outros. (PINO, 2009, p. 845) [grifo meu]

As perspectivas de Marx e Engels na obra de Vigotski são apontadas e defendidas por Pino nas pesquisas e reflexóes sobre história, cultura, desenvolvimento humano, linguagem, consciência e funçôes psicológicas superiores/culturais. A referência a essa matriz como contexto para interpretar conceitos ou ideias cujo sentido não foi claramente explicitado pelo autor parece ser uma garantia de fidelidade a esse pensamento, explicita Pino. (PINO, 2009, p. 96) 
Porque temia intepretaçóes equivocadas da obra de Vigotski, pedia "vigilância", pois o tratamento conceitual de vários termos utilizados pelo autor russo está ainda por ser analisado e compreendido. Qualquer desatenção ou precipitação pode desviar o leitor do caminho mais próximo do pretendido. Trabalhar as ideias de Vigotski foi, para Pino, sempre um desafio por ele assumido.

\section{MARX, ENGELS, VIGOTSKI E PINO}

No ensaio O social e o cultural na obra de Vigotski, Angel Pino (2000) analisa duas categorias fundamentais para a leitura do autor russo: a natureza social e a cultural das funçóes superiores. Vai ao Manuscrito de 1929 para - como sempre fazia - chegar ao núcleo central da obra do autor, e aponta que o materialismo histórico-dialético é o método de análise utilizado por Vigotski para elaborar essas duas categorias, assumindo como fontes, entre outras, a IV Tese sobre Feuerbach: "[...] mas a essência humana não é uma abstração inerente ao indivíduo singular. Em sua realidade, é o conjunto das relaçóes sociais [...]”. (MARX; ENGELS, 1996, p. 13) Nesse ensaio, Pino explica que Marx e Engels criticam o materialismo sensualista de Feuerbach e, por isso, marcam a vida do homem como o conjunto das relaçóes sociais. O argumento é claro, diz Pino:

[...] a maneira como os homens produzem/reproduzem, pelo trabalho social, as suas condiçóes de existência, físicas e sociais, representa o seu modo de vida próprio, o qual reflete mais precisamente o que eles são. Existe uma estreita interdependência entre o modo de ser dos homens (sua essência), seus modos de produção (condiçóes de produção) e o tipo de relaçóes sociais que deles decorre (MARX; ENGELS, 1982, pp. 70-71) (PINO, 2000, p. 62) [grifo do autor]

A obra $O$ significado histórico da crise na Psicologia - uma investigação metodológica, escrita por Vigotski em 1927, reflete o grande esforço para a construção de uma Psicologia Concreta que tivesse como matriz os "[...] princípios do materialismo dialético, particularmente 
no referente ao método, ao conceito de atividade e à origem social das funçóes psicológicas [...]". (SIRGADO, 1990, p. 63) ${ }^{3}$ Vigotski precisava deixar claro o que estava propondo e imagina-se a difícil tarefa que tinha pela frente: fazer a crítica já apontando o caminho; o que nos faz lembrar o mesmo esforço de Marx e Engels à sua época. Afirmou corajosamente que não haveria outra via para aplicar o marxismo na Psicologia que não fosse dependente da dialética geral, ou seja, que não abarcasse a natureza, o pensamento, a história. "Essa teoria do materialismo psicológico ou dialético da psicologia é o que considero a psicologia geral [...]", diz Vigotski (1991, p. 389).

Valiosa obra que nos aproxima da posição teórica de Vigotski em sua elaboração, O significado histórico da crise na Psicologia (1991), não deixa dúvidas quanto à sua proposta: um novo modelo de ciência que podemos encontrar na edificação da teoria histórico-cultural acerca do desenvolvimento humano. O último parágrafo dessa obra de Vigotski interessa-nos especialmente para compor as reflexóes deste texto, por indicar um possível caminho na compreensão das relaçóes - que venho tentando apreender - entre as obras de Marx e Engels, Vigotski e Angel Pino e o conceito de "homem novo" - transformado - que Vigotski assume de Marx.

$\mathrm{Na}$ futura sociedade, a psicologia será em realidade a ciência do homem novo. Sem ela, a perspectiva do marxismo e da história da ciência seria incompleta. Porém, sem dúvida, essa ciência do homem novo será também psicologia. Por isso, já hoje mantemos suas rédeas em nossas mãos. Não há necessidade de dizer que essa psicologia se parecerá táo pouco com a atual como, segundo palavras de Spinoza, a constelação de Cão se parece ao cachorro, animal que ladra (Ética, teorema 17, Escolio). (VYGOTSKI, 1991, p. 406) [tradução e grifo meu].

Não é demais retomar que uma teoria social da sociedade, sob essa perspectiva, requer análise teórica da produção das condiçôes materiais e simbólicas da vida social. Isso é "exigência que decorre do próprio objeto de pesquisa”, explica José Paulo Netto (2011, p. 48). Em Miséria 
da Filosofia (2009), escrito em 1847, Marx aborda as determinaçóes históricas das relaçóes sociais: a sociedade é o produto da ação recíproca entre os homens. Como produção histórica dos homens, a ação recíproca entre eles está em movimento - constitui-se totalidade dinâmica de caráter contraditório e mediada, analisa Paulo Netto (2011, p. 57) sobre o que afirma Marx (2009): "As relaçôes sociais estão intimamente ligadas às forças produtivas. Adquirindo novas forças produtivas, os homens transformam o seu modo de produção e, ao transformá-lo, alterando a maneira de ganhar a vida, eles transformam todas as suas relaçóes sociais [...]" (p. 125).

Vigotski, em seu intento de firmar a Psicologia Histórico-cultural, superando por incorporação as concepçóes vigentes de seu tempo, afirma:

Como um indivíduo só existe como um ser social, como um membro de algum grupo social em cujo contexto ele segue a estrada do desenvolvimento histórico, a composiçáo de sua personalidade e a estrutura de seu comportamento revestem-se de um caráter dependente da evoluçáo social cujos aspectos principais são determinados pelo grupo. (VIGOTSKI, 1930, p. 1)

Tal afirmação traz alguns elementos que marcam fortemente sua posição conceitual metodológica, como explica Pino (2005, p. 14): o que Vigotski escreveu nas décadas de 1920 e 1930 apresenta-se com surpreendente atualidade em relaçáo às questóes da natureza humana.

$\mathrm{Na}$ impossibilidade de nos estendermos demasiado nas reflexôes, a escolha foi por apontar aspectos da noção de homem novo em uma sociedade nova em Vigotski a partir das contribuiçóes de Angel Pino, que nos aproximam do materialismo histórico-dialético e trabalham com a ideia de natureza transformada pela/com a cultura (sem perder suas características) e com a noção de cultura materializada em natureza. (PINO, 2005, p. 53)

Vigotski (1930, p. 1) diz que: 
Realmente, a luta pela sobrevivência e a seleção natural, as duas forças motrizes da evolução biológica no mundo animal, perdem a sua importância decisiva assim que passamos a considerar o desenvolvimento histórico do homem. As novas leis que regulam o curso da história humana e que regem o processo de desenvolvimento material e mental da sociedade humana, agora tomam os seus lugares. [grifo meu]

Vigotski cita o Anti-Dühring ${ }^{4}$, mas parece que se refere, também, ao Prefácio à Contribuição à Crítica da Economia Política, escrito por Marx em 1859. Neste último, o autor analisa que, para produzir a vida, os homens estabelecem relações necessárias - não poderiam deixar de fazê-lo - independente da sua vontade e, ao se relacionarem e formarem a base econômica da sociedade, também formam a superestrutura jurídica, política, religiosa; o que corresponde à formação da consciência social. As novas leis que regulam o curso da história, portanto, as condiçóes materiais de vida, formam a consciência, e não o contrário. (MARX, 2010) É coerente assumir essa lei geral marxiana para estudar Vigotski, já que, para ele, segundo essa lei, o capitalismo corrompe a personalidade humana:

Em um dos extremos da sociedade, a divisão entre o trabalho intelectual e o físico, a separação entre a cidade e o campo, a exploração cruel do trabalho da criança e da mulher, a pobreza e a impossibilidade de um desenvolvimento livre e completo do pleno potencial humano, e no outro extremo, ócio e luxo; disso tudo resulta não só que o tipo humano originalmente único torna-se diferenciado e fragmentado em vários tipos nas diversas classes sociais que, por sua vez, permanecem em agudo contraste umas às outras, mas também na corrupção e distorção da personalidade humana e sua sujeição a um desenvolvimento inadequado, unilateral em todas estas diferentes variantes do tipo humano. (VIGOTSKI, 1930, p. 3) [grifo do autor] 
Sob a pressão de uma sociedade fundamentada nas relaçóes de exploração; onde, então, encontrar caminhos para a superação do que parece ser determinado e insuperável? Vigotski (1930, p. 4-5), no mesmo texto, pondera que o processo que mutila os humanos é inerente à sociabilidade capitalista, porém,

A mais fundamental e importante contradição em toda esta estrutura social consiste no fato de que, dentro dela, sob pressão inexorável, estão evoluindo forças para sua destruição, e estão sendo criadas as precondiçóes para sua substituiçáo por uma nova ordem baseada na ausência da exploraçáo do homem pelo homem $[\ldots]$.

Em seguida, remetendo a Marx, Vigotski fala do sistema educacional e, mais especificamente, da escola politécnica, que combina trabalho produtivo com a educação formal e física. Tal combinação - gênese do conceito de trabalho como princípio educativo e que se propóe à formação do homem omnilateral em busca da transformação radical da sociedade capitalista - pareceu a Vigotski ser uma das possibilidades de formação de pessoas plenamente desenvolvidas. Desenvolvimento que podemos entender como aquele que salta do reino da necessidade para o da liberdade, como o mesmo autor explica em outra obra. (VIGOTSKI, 1991, p. 406)

O que esses autores estão defendendo é uma nova ordem social, uma nova forma de organizaçáo social que não acontece naturalmente, mas que exige um longo período de resistência contra a opressão. Vigotski parece acreditar que "[...] paralelamente a esse processo, uma mudança na personalidade humana e uma alteração do próprio homem deve inevitavelmente acontecer [...]”. (VIGOTSKI, 1930, p. 8)

\section{CONSIDERAÇÕES FINAIS}

Em síntese, Vigotski aponta três raízes básicas para chegar à alteração do próprio homem - e sua liberação -, o que podemos entender 
como sua proposição para a constituição do homem novo: a destruição do capitalismo, a combinação dialética do trabalho físico e intelectual e as mudanças nas relaçôes interpessoais.

[...] a personalidade humana é formada basicamente pela influência das relaçôes sociais, i.e., o sistema do qual o indivíduo é apenas uma parte desde a infância mais tenra. "Minha relação para com meu ambiente", diz Marx, "é minha consciência". Uma mudança fundamental do sistema global dessas relaçôes, das quais o homem é uma parte, também conduzirá inevitavelmente a uma mudança de consciência, uma mudança completa no comportamento do homem. (VIGOTSKI, 1930, p.7)

Mas o autor russo, comprometido com sua proposição de elaborar uma teoria sólida sobre o desenvolvimento humano, bem como para delinear o papel da escola, insiste que "[...] as novas geraçóes e suas novas formas de educação representam a rota principal que a história seguirá para criar o novo tipo de homem [...]”. (VIGOTSKI, 1930, p.10)

O esforço de Angel Pino em direção à compreensão da teoria de Vigotski sobre a passagem da ordem do desenvolvimento natural para o cultural - o que fez parte fundamental de sua obra - bem pode ser aproximado ao de Vigotski:

Tendo dominado os processos que determinam sua própria natureza, o homem que hoje está lutando contra velhice e doenças, ascenderá, indubitavelmente, a um nível mais elevado e transformará sua própria organização biológica. Mas essa é a fonte do maior paradoxo histórico do desenvolvimento contido nessa transformação biológica do tipo humano, que ela é alcançada principalmente por meio da ciência, da educaçăo social e da racionalização dos modos de vida. A alteraçáo biológica do homem não representa uma condição prévia para esses fatores, mas, ao invés disso, é um resultado da liberação social do homem. (VIGOTSKI, 1930, p.11) 
Para Vigotski (1991, p. 406), a tarefa que se impóe é saltar do reino da necessidade para o reino da liberdade, ou seja, que os humanos possam dominar a si mesmos e, para tanto, hão de construir uma nova sociedade e, nela, uma nova psicologia que marque a virada no modo de conceber o homem social e seu desenvolvimento histórico e cultural, trazendo desdobramentos para a educação e para o processo de escolarização.

A instigante apresentação que escreveu no Editorial do número especial da Revista Educação \& Sociedade (2000) que organizou, dedicado a Lev Vigotski, é um dos momentos em que ficam evidentes a profundidade de conhecimento e o domínio do método de exposição de Angel Pino. Diz ele que o valor da obra de Vigotski está menos no volume, na quantidade de obras escritas, e mais na importância de sua visão de homem - que foi (e vai) na contramão dos aportes de sua época (e da nossa).

Ancorado em uma concepçáo materialista da história e armado de um modo de pensar dialético, Vigostki descobre no Homo o demiurgo de um mundo novo. Com efeito, a visão do homem que ele nos apresenta nos seus escritos é a de um ser que, emergindo da matéria e transpondo os seus limites no campo do imaginário e do simbólico, torna-se construtor do mundo e de si mesmo. (PINO, 2000, p. 8)

Como ser concreto, encarnado e criador de sua existência, faz a história ao mesmo tempo em que a vive e a reproduz. "Assume, para o bem ou para o mal, o controle da sua própria evolução [...]". (PINO, 2000, p. 8)

\section{REFERÊNCIAS}

MARX K. Manuscritos econômico-filosóficos. São Paulo: Boitempo, 2010. . Miséria da Filosofia: resposta à filosofia da miséria, do Sr. Proudhon. São Paulo: Expressão Popular, 2009. [Tradução de José Paulo Netto]. 
MARX, K; ENGELS, F. A Ideologia Alemã. (I - Feuerbach). 10. ed. São Paulo: Hucitec, 1996. [Tradução de José Carlos Bruni e Marco Aurélio Nogueira].

PAULO NETTO, J. Introdução ao estudo do método em Marx. São Paulo: Expressão Popular, 2011.

PINO, A. Ciência e Educação: a propósito do bicentenário do nascimento de Charles Darwin. Educ. Soc., Campinas, v. 30, n. 108, p. 845-866, out. 2009.

. As marcas do humano: às origens da constituiçáo cultural da criança na perspectiva de Lev S. Vigotski. São Paulo: Cortez, 2005.

. O social e o cultural na obra de Vigotski. Educ. Soc., Campinas, n. 71, 2000, p. 45-78.

. Editorial. Campinas, Educ. Soc. n. 71, 2000, p. 7-17.

. A escola e a construção da cidadania. In: COLETÂNEA CBE. Sociedade civil e educaçâo. Campinas: Papirus, 1992, p.15-25.

SIRGADO, A. P. A corrente sócio-histórica de psicologia: fundamentos epistemológicos e perspectivas educacionais. Em Aberto, Brasília, ano 9, n. 48, out./ dez. 1990, p. 60-67.

VIGOTSKY, L. S. (1930). A transformação socialista do homem. Disponível em: $<$ https://marxists.anu.edu.au/portugues/vygotsky/1930/mes/transformacao.

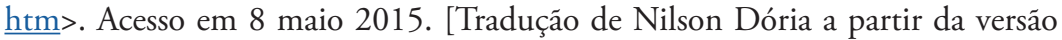
em inglês The socialist alteration of man para Marxists Internet Archive].

. The history of higher mental functions. In: . The Collected Works. v. 4. Nova Iorque: Plenum, 1997.

. Obras Escogidas I. Madrid: Visor, 1991. [Tradução de José Maria Bravo].

. El significado histórico de la crisis de la psicología. Una investigación metodológica. In: Obras Escogidas I. Madrid: Visor, 1991. [Tradução de José Maria Bravo].

VIGOTSKI, L. S.; LURIA, A. R. Studies of the history of behavior: ape, primitive and child. New York: Lawrence Erlbaum, 1992. [Edição e tradução de I. GolodeJane E. Knox].

- A história do comportamento: o macaco, o primitivo e a criança. Porto Alegre: Artes Médicas, 1996. [Tradução de Lólio Lourenço de Oliveira]. 


\section{NOTAS}

1. Angel Pino. Anotações de aula, 1999.

2. Adotaremos a grafia Vigotski, exceto nos casos de referências diretas às obras do autor, quando reproduziremos a escrita nelas presentes.

3. Algumas obras estão assinadas como Angel Pino e outras como Angel Pino Sirgado.

4. Originalmente publicado em 1878, Anti-Dühring é uma obra na qual Engels faz uma exposição completa do marxismo, versando praticamente sobre a Filosofia, o Direito e as diferentes leis e conceitos econômicos.

Recebido em 15 de junho de 2015.

Aprovado em 30 de julho de 2015.

DOI: http://dx.doi.org/10.1590/CC0101-32622015V35ESPECIAL154118 